\title{
Optimasi Vigenere Cipher Menggunakan Bitswap dan Transposisi Acak pada Citra RGB
}

Vigenere Cipher Optimization using Bitswap and Random Transposition for RGB Image

\author{
Luluk Andriani ${ }^{1}$, Rihartanto ${ }^{2 *}$, Arief Bramanto Wicaksono Putra ${ }^{3}$ \\ 1,2,3 Jurusan Teknologi Informasi, Politeknik Negeri Samarinda \\ E-mail: '1ulukandriani97@gmail.com, ${ }^{2}$ rihart.c@gmail.com, ${ }^{3}$ ariefbram@gmail.com
}

\begin{abstract}
Abstrak
Meningkatnya pertukaran informasi secara digital baik dalam hal kualitas maupun kuantitas merupakan salah satu alasan utama tentang pentingnya pengamanan berbagai bentuk data dan informasi. Tindakan ini menjadi semakin penting mengingat bahwa sebagian informasi bersifat pribadi atau rahasia. Dalam penelitian ini, pengamanan citra dilakukan menggunakan Vigenere Cipher (VC) yang dioptimasi menggunakan bitswap dan transposisi acak. VC adalah algoritma enkripsi sederhana yang ditujukan untuk pengamanan data berupa teks, sehingga sebenarnya kurang cocok untuk enkripsi citra. Hasil penelitian menunjukkan bahwa bitswap dan transposisi acak mampu meningkatkan kinerja VC dalam enkripsi citra. Kinerja optimasi VC pada enkripsi citra, dinilai secara visual serta diukur menggunakan Shannon entropi dan koefesien korelasi. Entropi tertinggi diperoleh dari VC yang dioptimasi dengan bitswap dan transposisi acak yaitu rata-rata sebesar 7.9582. Peningkatan rata-rata entropi ini adalah sebesar 37\% dibanding entropi citra aslinya. Koefesien korelasi hasil enkripsi rata-rata adalah sebesar 0.0195, angka ini sudah sangat mendekati 0 (nol) yang berarti perubahan nilai pada setiap piksel hasil enkripsi sama sekali tidak dipengaruhi oleh nilai piksel aslinya.
\end{abstract}

Kata kunci : optimasi vigenere cipher, bitswap, transposisi acak, entropi, koefesien korelasi

\begin{abstract}
The increasing exchange of digital information both in terms of quality and quantity is one of the main reasons for the importance of securing various forms of data and information. This action becomes even more important given that some information is private or confidential. In this study, image security was carried out using Vigenere Cipher (VC) which was optimized using bitswap and random transposition. $V C$ is a simple encryption algorithm intended for data security in the form of text, so it is actually not suitable for image encryption. The results showed that bitswap and random transposition can improve VC performance in image encryption. VC optimization performance on image encryption is assessed visually and measured using Shannon entropy and correlation coefficients. The highest entropy was obtained from VC which was optimized with bitswap and random transposition, which was an average of 7.9582. This average increase in entropy is 37\% compared to the entropy of the original image. Correlation coefficient of the encryption results on average is 0.0195 , this number is very close to 0 (zero) which means that the change in the value of each pixel from the encryption result is not influenced by the original pixel value.
\end{abstract}

Keywords: optimization vigenere cipher, bitswap, random transposition, entropy, correlation coefficient 


\section{PENDAHULUAN}

Meningkatnya pertukaran informasi secara digital baik dalam hal kualitas maupun kuantitas merupakan salah satu alasan utama tentang pentingnya pengamanan berbagai bentuk data dan informasi. Pengamanan tersebut berfungsi untuk melindungi informasi dari pihak yang tidak bertanggung jawab baik terhadap pemalsuan, pencurian maupun pengubahan informasi secara ilegal. Terdapat beberapa cara untuk melakukan pengamanan informasi, diantaranya dengan menggunakan teknik penyandian data yang disebut dengan kriptografi.

Kriptografi adalah salah satu metode atau teknik yang dapat digunakan untuk melindungi informasi. Kriptografi merupakan ilmu penulisan rahasia dengan tujuan menyembunyikan makna pesan. Proses kriptografi dibagi menjadi dua bagian, yaitu proses enkripsi dan proses dekripsi. Enkripsi merupakan proses mengubah pesan agar menjadi bentuk yang tidak dimengerti, sedangkan dekripsi merupakan proses untuk mengembalikan pesan yang dirahasiakan. Sementara pesan dalam konteks digital dapat berupa teks, citra, audio atau video.

Berbeda dengan teks yang terdiri dari karakter berupa huruf dan angka serta simbol, citra adalah kumpulan dari piksel-piksel yang memiliki nilai intensitas yang berbeda-beda. Sebuah citra digital dapat diwakili oleh sebuah matriks dua dimensi yang terdiri dari $m$ kolom dan $n$ baris. Perpotongan antara kolom dan baris ini disebut piksel atau elemen terkecil dari sebuah citra. Nilai intensitas setiap piksel berada pada rentang 0 sampai 255. Citra dapat dihasilkan menggunakan akuisitor seperti kamera atau scanner, atau dibuat menggunakan software pengolah grafis.

Dalam penelitian ini Vigenere Cipher (VC) digunakan untuk melakukan enkripsi dan dekripsi terhadap citra. VC adalah salah satu jenis kriptografi klasik yang menerapkan metode substitusi polialfabetik dan termasuk dalam kategori kunci simetris karena kunci yang sama digunakan pada proses enkripsi dan dekripsi. Formula asli VC hanya digunakan untuk menyandikan 26 huruf alphabet [1][2]. Untuk tujuan penyandian citra, formula asli ini diperluas sehingga rentang nilainya berubah dari 26 karakter menjadi 256 karakter. Jumlah ini diperlukan agar dapat mengakomodasi nilai piksel yang berada pada rentang 0 sampai dengan 255 [3][4].

Terdapat banyak penelitian yang telah dilakukan untuk meningkatkan kinerja VC. Diantaranya dengan memodifikasi kunci yang digunakan seperti varying key, multi-cycle key [5], kunci geser[6], one time pad (OTP) [7] serta menggunakan citra grayscale sebagai kunci enkripsi[4]. Beberapa lainnya melakukan peningkatan dengan $\mathrm{VC}$ dengan algoritma lain seperti dengan transposisi kolumnar[8], Beaufort Chiper[7] dan Goldbach Codes[1]. Sementara optimasi VC pada citra diantaranya dengan kunci random[1] dan bit circular shift [3].

Penggunaan one time pad [7], kunci random [1] dan kunci citra grayscale[4] mampu menghilangkan sifat berulang dari VC karena panjang kunci sama dengan panjang pesan yang dienkripsi. Sedangkan pada penggunaan kunci geser[6] dan multi-cycle key[5], keduanya mempertahankan penggunaan kunci pendek namun juga mampu menghilangkan sifat kemunculan karakter berulang yang merupakan kelemahan dari VC.

Dalam penelitian ini, bitswap dan transposisi acak digunakan untuk mengoptimasi algoritma VC pengamanan informasi dalam bentuk citra. Kedua metode optimasi ini dipilih karena memiliki algoritma yang sederhana sehingga mudah untuk diaplikasikan. Mirip dengan [5] dan [6], dalam penelitian ini juga mempertahankan penggunaan kunci yang pendek pada proses enkripsi dan dekripsi.

\section{METODE PENELITIAN}

\subsection{Vigenere Cipher}

Vigenere Cipher (VC) merupakan pengembangan dari algoritma caesar cipher. Algoritma ini menerapkan operasi modulus untuk mendapatkan sandi dari setiap karakter, atau untuk mendapatkan kembali karakter asli yang sudah disandikan. Versi asli dari VC hanya digunakan untuk menyandikan 26 huruf alphabet, menggunakan formula [3][9] yang ditunjukkan Persamaan (1) untuk melakukan enkripsi dan Persamaan (2) untuk melakukan 
deskripsi. $\mathrm{P}_{\mathrm{i}}$ adalah karakter pesan ke-i, $\mathrm{C}_{\mathrm{i}}$ adalah karakter cipher ke-i, dan $\mathrm{K}_{\mathrm{i}}$ adalah karakter kunci ke-i.

$$
\begin{aligned}
& C_{i}=\left(P_{i}+K_{i}\right) \bmod 26 \\
& P_{i}=\left(C_{i}-K_{i}\right) \bmod 26
\end{aligned}
$$

Untuk tujuan implementasi pada citra, formula VC ini perlu dimodifikasi mengingat rentang nilai pada piksel yang lebih lebar. Rentang nilainya diperluas menjadi 256 karakter untuk mengakomodasi nilai piksel yang memiliki rentang 0 sampai dengan 255. Modifikasi rumus VC menjadi VC256 [3] ditunjukkan pada Persamaan (3) untuk enkripsi dan Persamaan (4) untuk dekripsi.

$$
\begin{aligned}
& C_{i}=\left(P_{i}+K_{i}\right) \bmod 256 \\
& P_{i}=\left(C_{i}-K_{i}\right) \bmod 256
\end{aligned}
$$

Misalkan nilai sebuah piksel adalah 120 dengan kunci adalah karakter 'A'. Kunci terlebih dahulu diubah menjadi nilai ASCII yaitu 65. Enkripsi dilakukan dengan menggunakan Persamaan (3) yaitu $(120+65)$ mod 256 sehingga diperoleh nilai piksel baru yaitu 185, sementara dekripsi dilakukan menggunakan Persamaan (4) yaitu (185 - 65) mod 256 sehingga diperoleh nilai piksel awal yaitu 120 .

\subsection{Bitswap}

Bitswap (pertukaran bit) merupakan teknik yang digunakan untuk mengubah suatu nilai desimal tertentu dengan cara melakukan pertukaran posisi antar bit. Pada penelitian ini digunakan dua teknik bitswap. Teknik pertama adalah dengan melakukan pertukaran posisi antara kelompok bit MSB dan kelompok bit LSB (Gambar 1.a yang akan disebut bitswap I). Teknik yang kedua dilakukan dengan pencerminan antara kelompok bit MSB dan kelompok bit LSB, sehingga pertukaran bit yang terjadi adalah bit ke-1 dengan bit ke-8, bit ke-2 dengan bit ke-7, dan seterusnya seperti ditunjukkan pada Gambar 1.b yang akan disebut bitswap II.

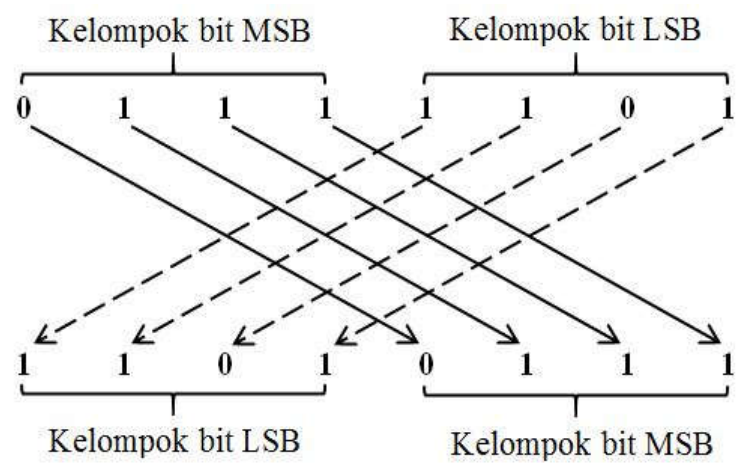

(a)

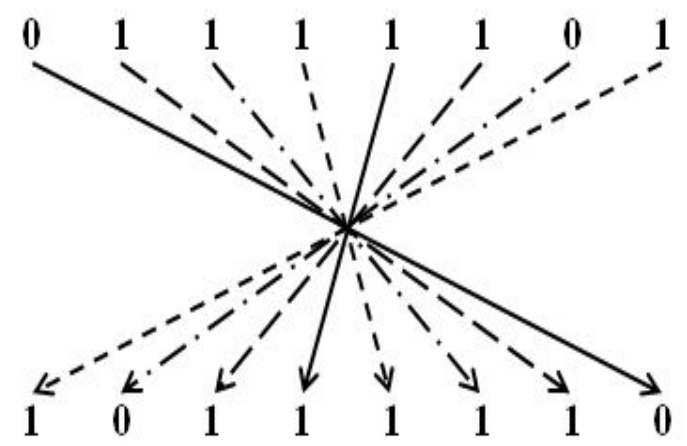

(b)

Gambar 1 a.Pertukaran pada kelompok bit. b.Pertukaran bit dengan pencerminan

Dalam penelitian ini bitswap pertama digunakan untuk mengubah nilai piksel sebelum dilakukan proses enkripsi, hasil enkripsi selanjutnya diubah kembali dengan bitswap kedua. Urutan sebaliknya digunakan pada proses dekripsi. Misalkan nilai sebuah piksel adalah 77 yang dalam bilangan biner adalah 01001101, maka menggunakan teknik bitswap pertama akan menghasilkan 11010100 sedangkan menggunakan teknik kedua akan menghasilkan 10110010. Tujuan penggunaan bitswap ini adalah untuk menghilangkan pola berulang yang merupakan salah satu karakteristik dari VC. 


\subsection{Transposisi Baris dan Kolom}

Transposisi baris adalah perpindahan baris tertentu ke baris lainnya demikian juga dengan transposisi kolom yaitu perpindahan kolom tertentu ke kolom lainnya. Penentuan posisi baris atau kolom transposisi dihasilkan dengan menggunakan pembangkit bilangan acak tanpa adanya perulangan[10]. Bilangan acak yang dihasilkan harus sebanyak jumlah kolom dan jumlah baris pada citra. Proses transposisi baris dan kolom ditunjukkan pada Gambar 2. Transposisi acak ini digunakan untuk meningkatkan keacakan citra hasil enkripsi.

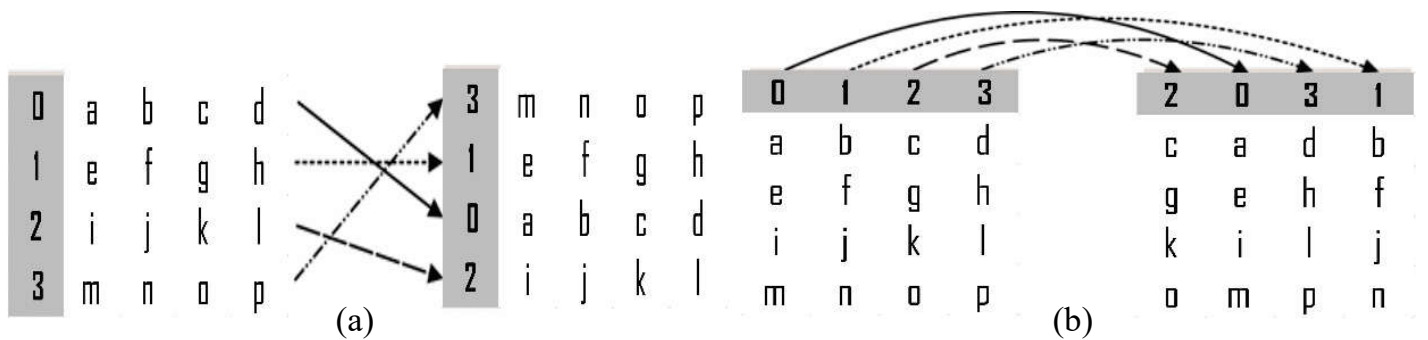

(a)

Gambar 2 a. Transposisi Baris b.Transposisi Kolom

\subsection{Implementasi Bitswap dan Transposisi Acak Untuk Optimasi Vigenere Cipher}

Dalam penelitian ini optimasi VC dilakukan dua tahap. Tahap pertama dilakukan pada proses enkripsi dan dekripsi dengan menerapkan bitswap. Bitswap I digunakan untuk mengubah nilai desimal dari piksel sebelum dilakukan enkripsi dengan VC. Bitswap II dilakukan pada hasil VC sehingga secara keseluruhan terjadi tiga kali perubahan nilai pada setiap piksel dari citra. Proses dekripsi setiap piksel dilakukan dalam urutan yang berlawanan dengan proses enkripsi. Secara lengkap implementasi bitswap untuk melakukan optimasi VC pada pengamanan citra ditunjukkan pada Gambar 3.

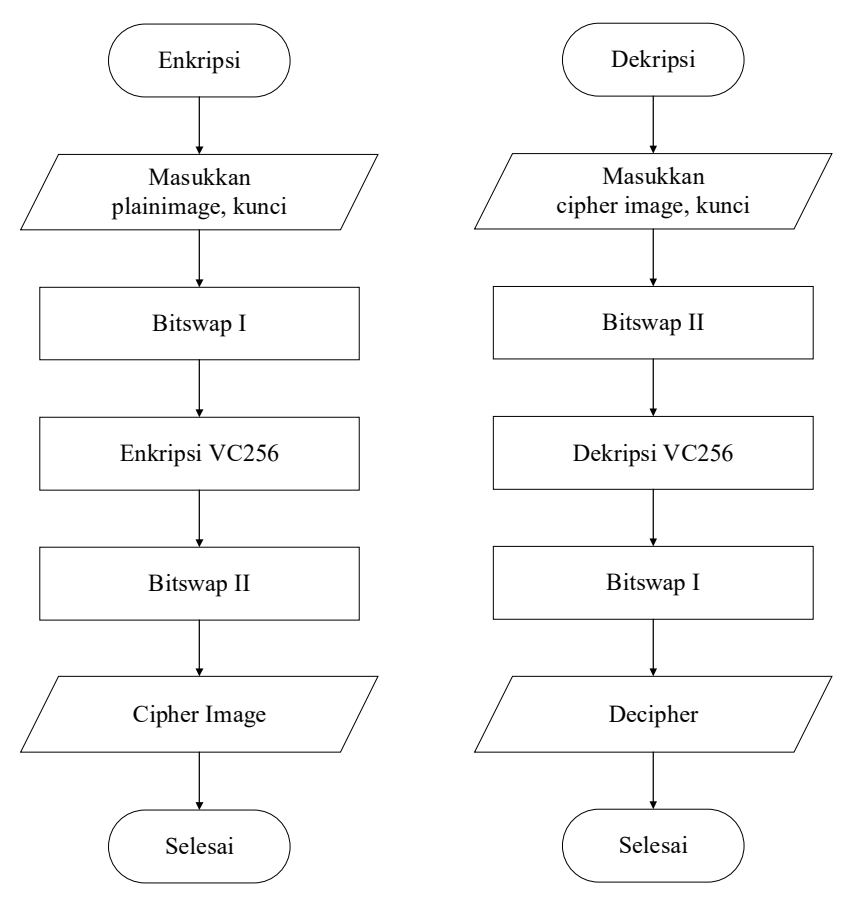

Gambar 3 Flowchart Enkripsi dan Dekripsi

Misalkan nilai sebuah piksel adalah 175 dalam bilangan biner adalah 10101111. Dan sebuah kunci 'A' dalam ASCII yaitu 65. Dilakukan bitswap tipe I menjadi 11111010 dalam bilangan desimal adalah 250. Enkripsi dilakukan dengan Persamaan (3) yaitu $(250+65)$ mod 256 diperoleh nilai piksel 59 dalam bilangan biner 00111011. Dilakukan kembali bitswap tipe II 
menjadi 11011100 dalam bilangan desimal adalah 220. Sehingga nilai awal piksel adalah 175 setelah dilakukan optimasi diperoleh nilai piksel baru yaitu 220 .

Tahap kedua, optimasi dilakukan terhadap hasil enkripsi yang sudah dioptimasi dengan bitswap. Optimasi terhadap hasil enkripsi ini dilakukan menggunakan transposisi acak. Urutan acak dari baris dan kolom tujuan transposisi diperoleh dengan menggunakan pembangkit bilangan random yang tersedia pada tools pemrograman. Keacakan urutan transposisi yang dihasilkan sangat dipengaruhi oleh seed random. Sehingga perlu dipastikan bahwa setiap kunci enkripsi yang digunakan dapat menghasilkan bilangan yang berbeda untuk digunakan sebagai seed random. Seed random diperoleh dengan menggunakan Persamaan (5)[10], dimana $\mathrm{k}_{\mathrm{i}}$ adalah karakter kunci ke-i dan i adalah urutan karakter kunci dimulai dari nol.

$$
\text { seed }=\sum_{i=0}^{n}\left(k_{i}^{2} \times i\right)(5)
$$

Sebagai contoh terdapat tiga kunci yang berbeda-beda yaitu 'abc', 'bac', dan 'cab'. Setiap karakter diubah menjadi ASCII yaitu $\mathrm{a}=97, \mathrm{~b}=98, \mathrm{c}=99$. Dengan menggunakan Persamaan (5), untuk kunci pertama yaitu $\left(97^{2} * 0\right)+\left(98^{2} * 1\right)+\left(99^{2} * 2\right)$ di peroleh nilai seed 29206. Dengan cara yang sama seed yang diperoleh dari kunci kedua adalah 29001 dan dari kunci ketiga adalah 28617. Dari ketiga kunci dihasilkan nilai seed yang berbeda meskipun karakter yang digunakan sama. Hal ini menunjukkan bahwa posisi dari karakter mempengaruhi nilai seed yang dihasilkan.

Implementasi transposisi acak untuk melakukan optimasi hasil enkripsi pada pengamanan citra dilakkan mengikuti algoritma berikut:

1. Masukkan citra hasil enkripsi yang sudah dioptimasi dengan bitswap

2. Bangkitkan bilangan random sebanyak jumlah baris dari citra

3. Bangkitkan bilangan random sebanyak jumlah kolom dari citra

4. Pindahkan baris citra mulai dari baris ke- 0 sampai baris ke- $n$, ke posisi baru sesuai bilangan acak yang dihasilkan pada nomor 3 .

5. Pindahkan baris citra mulai kolom ke- 0 sampai kolom ke- $n$, ke posisi baru sesuai bilangan acak yang dihasilkan pada nomor 4 .

6. citra hasil transposisi baris dan kolom ini merupakan cipherimage hasil optimasi

Sebagai contoh terdapat citra berukuran $3 \times 3$ yang ditunjukkan Gambar 4.a. Bilangan acak yang dihasilkan antara 0 sampai 2 . Misalkan $[2,0,1]$ untuk baris dan $[1,2,0]$ untuk kolom. Maka hasil transposisi acak ditunjukkan pada Gambar 4.b untuk baris dan Gambar 4.c untuk kolom.

$\begin{array}{cccc} & 0 & 1 & 2 \\ 0 & 211 & 80 & 210 \\ 1 & 191 & 60 & 154 \\ 2 & 161 & 100 & 81\end{array}$

(a)

$\begin{array}{cccc} & 0 & 1 & 2 \\ 2 & 161 & 100 & 81 \\ 0 & 211 & 80 & 210 \\ 1 & 191 & 60 & 154\end{array}$

(b)

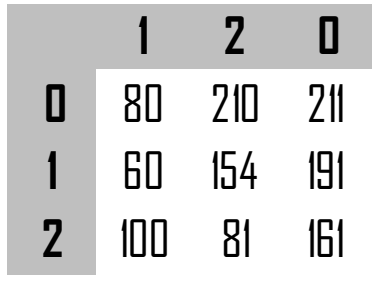

(c)

Gambar 4 a. Citra Asli b. Transposisi Baris c. Transposisi Kolom

Untuk mengukur kinerja dari enkripsi digunakan shannon entropy ditunjukkan pada Persamaan (6) dan koefesien korelasi yang ditunjukkan pada Persamaan (7), sementara kinerja hasil dekripsi diukur dengan koefesien korelasi. Shannon entropy terutama digunakan untuk mengukur keacakan hasil enkripsi dimana $P\left(x_{i}\right)$ merupakan probabilitas kemunculan nilai tertentu. Nilai entropi tertinggi untuk citra yaitu 8 yang diperoleh dari $\log 2(255)$, angka tersebut 
menunjukkan keacakan dari hasil enkripsi sangat tinggi. Sementara koefesien korelasi digunakan untuk mengukur seberapa jauh perubahan nilai piksel hasil enkripsi serta seberapa tepat hasil dekripsinya. Nilai koefesien korelasi berada pada rentang -1 sampai dengan 1, dimana 0 menunjukkan tidak adanya korelasi antar nilai piksel asli dengan nilai piksel hasil enkripsi, sementara 1 atau -1 menunjukkan adanya korelasi yang kuat antar nilai piksel asli dengan nilai piksel hasil enkripsi.

$$
\begin{aligned}
& H(x)=-\sum_{i=1}^{n} P\left(x_{i}\right) \log 2 P\left(x_{i}\right)(6) \\
& r=\frac{\sum_{i=1}^{n}(x i-\bar{x})(y i-\bar{y})}{\sqrt{\sum_{i=1}^{n}\left(x_{i}-\bar{x}\right)^{2}} \sqrt{\sum_{i=1}^{n}\left(y_{i}-\bar{y}\right)^{2}}}
\end{aligned}
$$

Dalam banyak penelitian, nilai entropi sering kali diukur berdasarkan nilai piksel dari sebuah citra. Namun penelitian ini, entropi diukur berdasarkan nilai jarak antar piksel. Hal ini diperlukan karena jika entropi diukur berdasarkan nilai piksel maka fungsi transposisi acak yang digunakan untuk melakukan optimasi hasil enkripsi dengan VC dan bitswap tidak memiliki pengaruh pada nilai entropi. Hal ini dikarenakan pada transposisi, yang berubah hanya posisi piksel, bukan nilai piksel. Pengukuran jarak antar piksel dilakukan menggunakan pola pembacaan zig-zag yang digunakan pada kompresi JPEG seperti yang ditunjukkan pada Gambar 5. Pola pembacaan zig-zag ini digunakan untuk mendapatkan jarak piksel yang saling berdekatan, baik pada citra asli maupun citra hasil enkripsi.

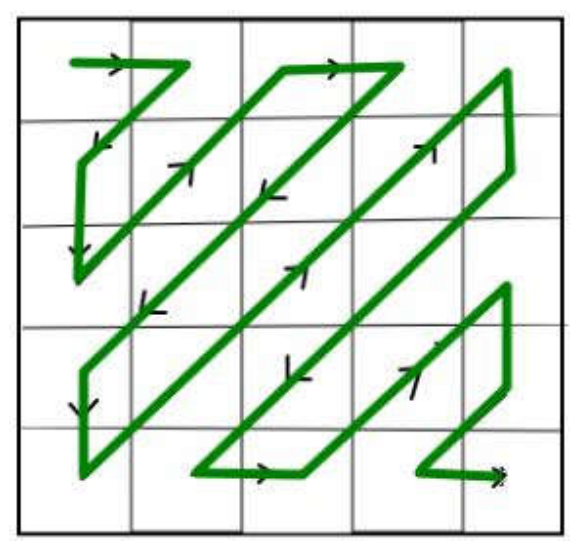

Gambar 5 Pembacaan piksel dengan pola Zig-Zag

\section{HASIL DAN PEMBAHASAN}

Citra yang digunakan untuk pengujian adalah citra yang umum digunakan dalam penelitian yang berhubungan dengan image processing, yaitu lena, baboon dan peppers. Ketiga citra memiliki dimensi yang sama yaitu $255 \times 255$ piksel yang disimpan dalam format lossy yaitu JPG. Hasil enkripsi dan hasil optimasinya disimpan sebagai format lossless yaitu PNG. Kunci yang digunakan untuk proses enkripsi dan dekripsi adalah 'ab123@'.

Pengukuran kinerja enkripsi dilakukan dengan cara membandingkan antara citra asli dengan citra hasil enkripsi menggunakan VC, VC yang dioptimasi dengan bitswap, dan VC yang dioptimasi dengan bitswap dan transposisi acak. Hasil enkripsi secara visual ditunjukkan pada Tabel 1, dan kinerja enkripsi beserta optimasinya ditunjukkan pada Tabel 2. Sementara Tabel 3 menunjukkan pengukuran kinerja proses dekripsi dengan cara membandingkan citra asli dengan citra hasil dekripsi. 
Tabel 1 Hasil Enkripsi Citra Secara Visual

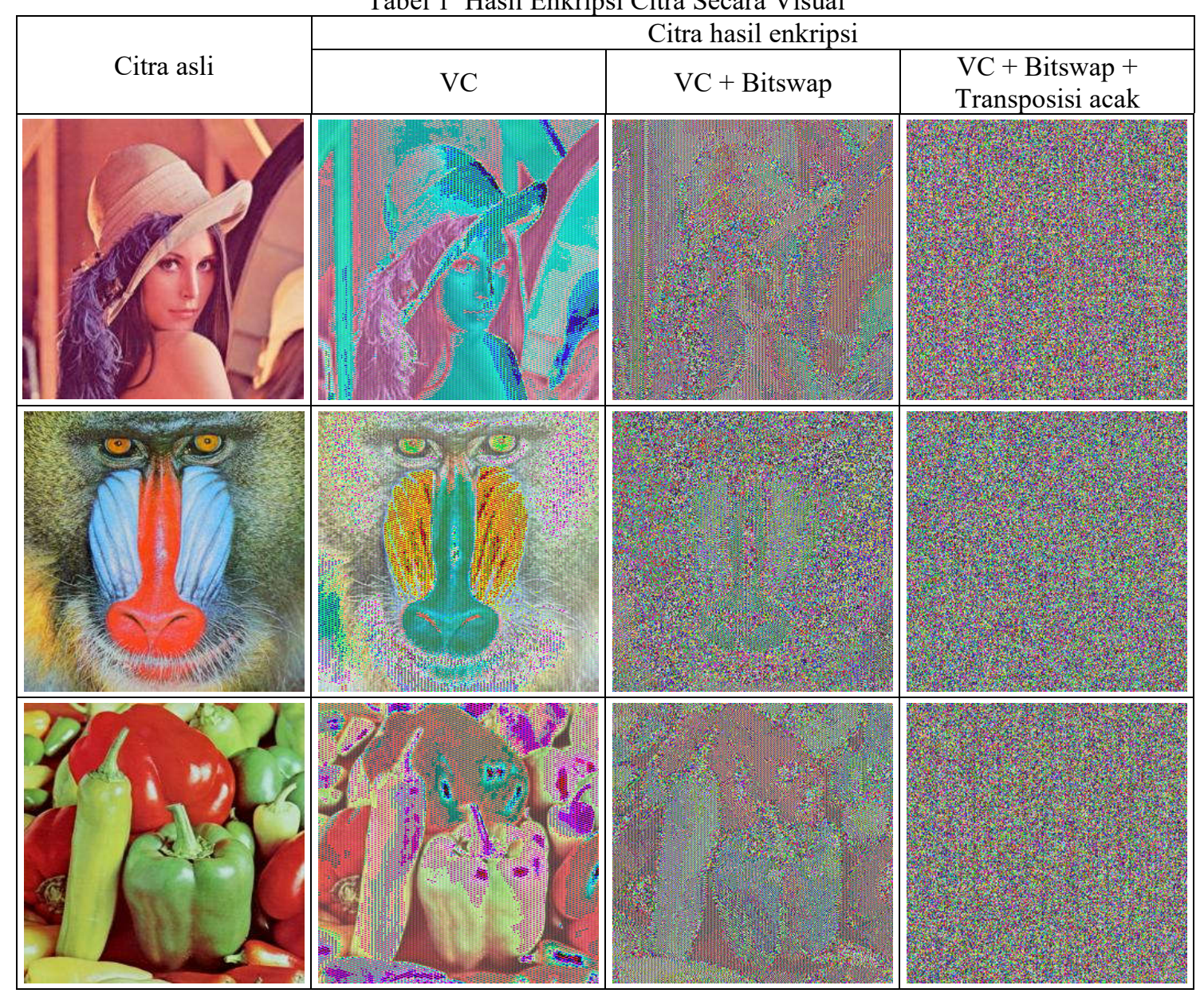

Pada Tabel 1, untuk seluruh citra uji terlihat bahwa citra hasil enkripsi menggunakan VC masih menunjukkan karakteristik citra aslinya, hanya komposisi warnanya saja yang berubah. Hal ini disebabkan karena VC sejatinya memang ditujukan untuk enkripsi teks, bukan citra. Optimasi VC menggunakan bitswap menunjukkan kinerja yang lebih baik, namun jika disandingkan dengan citra aslinya, secara visual masih ada sebagian bentuk dari citra asli yang dapat dikenali. Sementara optimasi dengan bitswap dan transposisi acak memberikan kinerja yang terbaik karena sudah tidak lagi menunjukkan ciri-ciri dari citra asli.

Tabel 2 Kinerja Hasil Enkripsi

\begin{tabular}{|c|c|c|c|c|c|c|c|}
\hline \multirow{2}{*}{ Citra } & \multicolumn{4}{|c|}{ Entropi } & \multicolumn{3}{c|}{ Koefesien Korelasi } \\
\cline { 2 - 8 } & Asli & VC & $\begin{array}{c}\text { VC+ } \\
\text { Bitswap }\end{array}$ & $\begin{array}{c}\text { VC+ } \\
\text { Bitswap+ } \\
\text { Transp. Acak }\end{array}$ & VC & $\begin{array}{c}\text { VC+ } \\
\text { Bitswap }\end{array}$ & $\begin{array}{c}\text { VC+ } \\
\text { Bitswap+ } \\
\text { Transp. Acak }\end{array}$ \\
\hline Lena.jpg & 5,3278 & 6,9430 & 7,6139 & 7,9240 & -0.2307 & 0.0588 & 0.0335 \\
\hline Baboon.jpg & 6,6687 & 7,4789 & 7,8268 & 7,9806 & -0.1356 & 0.0277 & 0.0037 \\
\hline Peppers.jpg & 5,4409 & 7,0066 & 7,6537 & 7,9700 & 0.2516 & 0.1386 & 0.0212 \\
\hline Rata-rata & 5.8125 & 7.1428 & 7.6981 & 7.9582 & -0.0382 & 0.0750 & 0.0195 \\
\hline
\end{tabular}

Kinerja enkripsi citra diukur menggunakan entropi dan koefesien korelasi, seperti ditunjukkan pada Tabel 2. Entropi digunakan untuk mengukur peningkatan keacakan citra hasil enkripsi, sementara koefesien korelasi digunakan untuk menilai seberapa besar pengaruh nilai 
piksel asal terhadap nilai hasil enkripsinya. Koefesien korelasi juga digunakan untuk mengukur seberapa tepat hasil dekripsi dibandingkan dengan citra aslinya.

Jika diukur berdasarkan nilai pikselnya, nilai entropi ketiga citra uji berturut-turut adalah 7.2970, 7.5699 dan 7.3610 masing-masing untuk lena, baboon dan peppers. Operasi VC dan bitswap yang mengakibatkan perubahan nilai piksel secara langsung juga mengakibatkan perubahan nilai entropi. Namun nilai entropi tidak mengalami perubahan karena adanya operasi transposisi acak yang mengakibatkan perubahan posisi piksel tanpa mengubah nilai pikselnya. Untuk dapat mengukur keacakan akibat operasi transposisi maka entropi dihitung berdasarkan jarak antar piksel. Sehingga didapatkan nilai entropi berdasarkan jarak antar piksel untuk ketiga citra asli tersebut adalah adalah 5.3278, 6.6687 dan 5.4409. Nilai ini lebih rendah dibanding dengan entropi berdasarkan nilai piksel. Hal ini menunjukkan bahwa terdapat banyak nilai piksel yang saling berdekatan, sehingga memberikan nilai jarak yang sama.

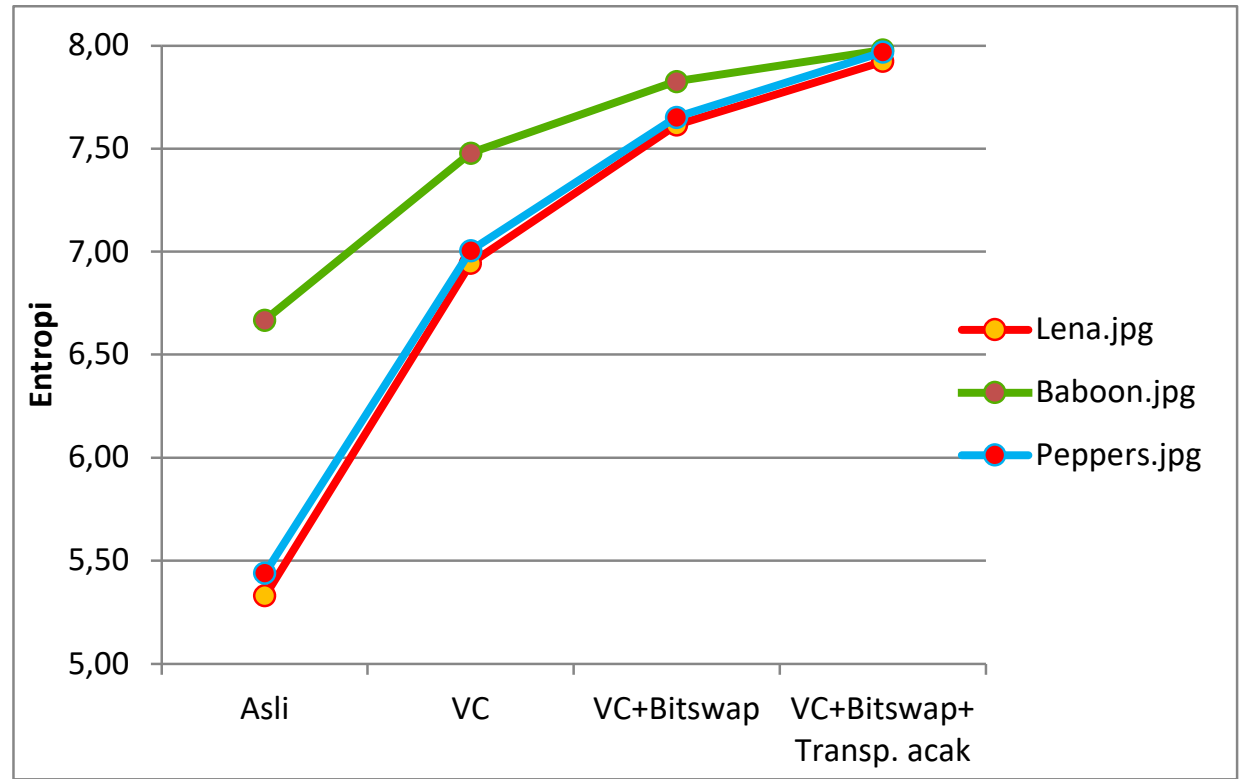

Gambar 6 Nilai entropi citra asli dan hasil enkripsi

Seperti ditunjukkan pada Gambar 6, setiap operasi meningkatkan nilai entropi dari citra aslinya. Dibandingkan dengan entropi citra asli, peningkatan rata-rata akibat operasi VC adalah sebesar 1.3304, akibat operasi VC dan bitswap adalah sebesar 1.8857 dan akibat operasi VC dan bitswap dan transposisi acak adalah sebesar 2.1457. Dari sini terlihat bahwa bitswap dan transposisi acak berhasil meningkatkan kinerja dari VC dalam pengamanan citra digital. Optimasi yang dilakukan memang memberi peningkatan keacakan yang signifikan pada hasil enkripsi. Rata-rata entropi tertinggi adalah sebesar 7.9582. Nilai ini sangat mendekati 8 yang merupakan entropi tertinggi untuk citra.

Demikian pula dengan nilai koefesien korelasinya seperti ditunjukkan pada Gambar 7. Optimasi VC menggunakan bitswap serta bitswap dan transposisi acak, secara umum menunjukkan bahwa nilai piksel hasil enkripsi menunjukkan tidak adanya korelasi antara nilai piksel asal dengan nilai piksel hasil enkripsi. Koefesien korelasi pada VC yang relatif lebih tinggi dibanding dengan hasil optimasinya, diantaranya dikarenakan adanya sifat berulang penggunaan kunci enkripsi pada proses VC. 


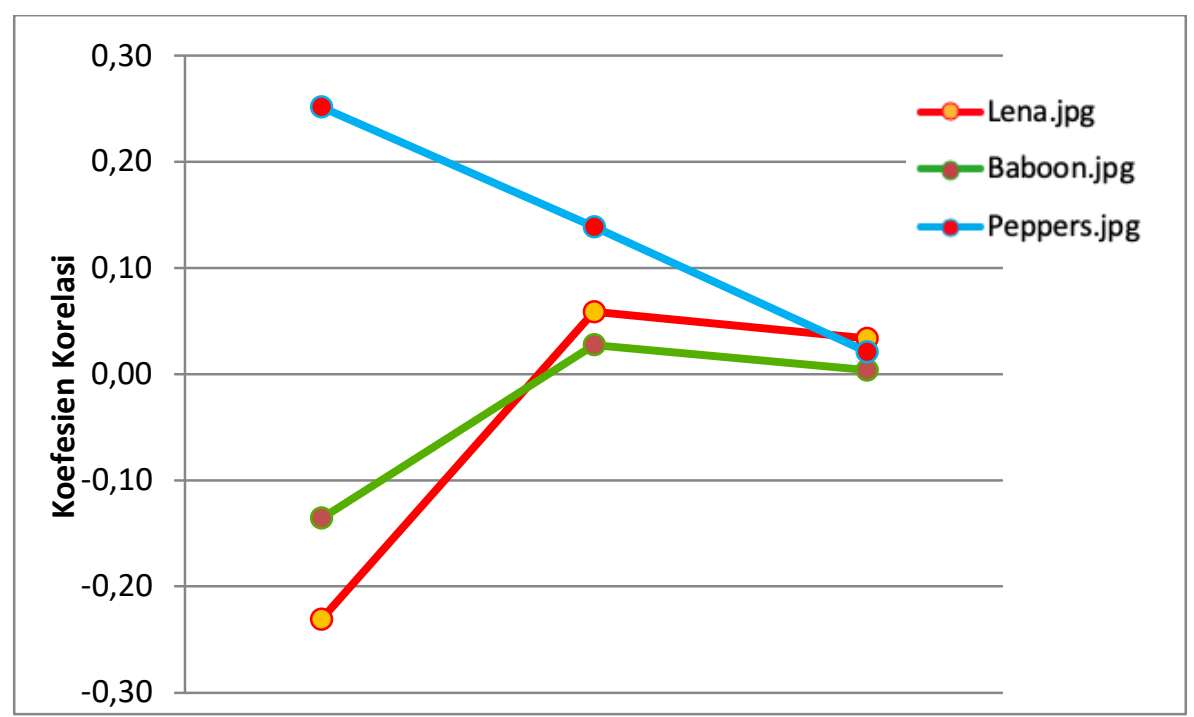

Gambar 7 Koefesien korelasi hasil enkripsi

Tabel 3. Hasil Dekripsi

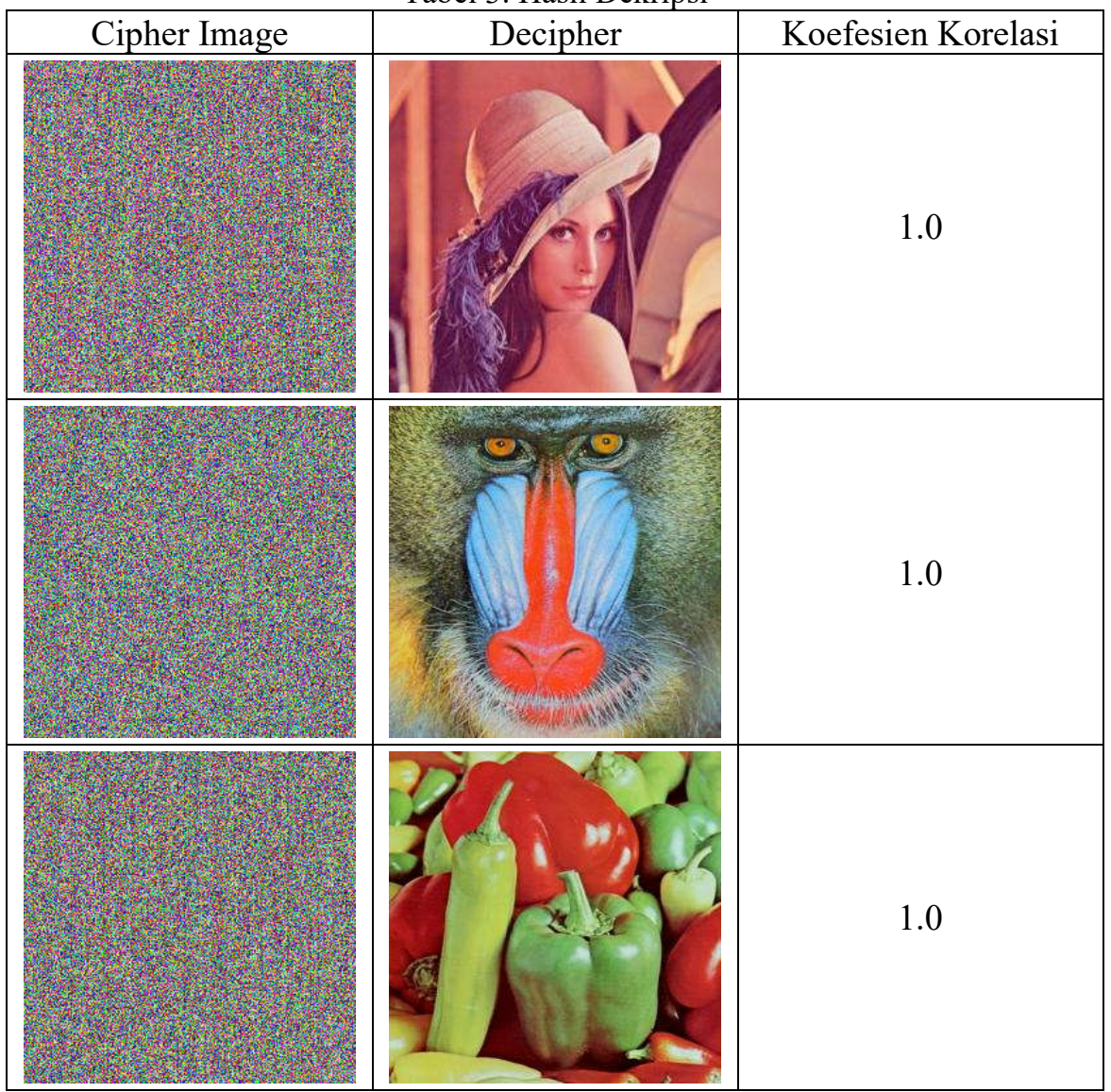

Proses dekripsi dari citra hasil enkripsi mampu menghasilkan citra yang persis sama dengan citra aslinya. Koefesien korelasi hasil dekripsi serta hasilnya secara visual ditunjukkan pada Tabel 3. Nilai koefesien korelasi yaitu 1.0, membuktikan bahwa nilai setiap piksel pada citra hasil dekripsi tepat sama dengan nilai piksel dari citra asli.

Dari kedua proses ini dapat diartikan bahwa optimasi menggunakan bitswap dan transposisi acak mampu memperbaiki kinerja algoritma $\mathrm{VC}$ untuk pengamanan data berupa citra RGB. Dimana citra hasil enkripsi tersebut dapat dikembalikan ke bentuk aslinya dengan tepat. 


\section{KESIMPULAN DAN SARAN}

Penelitian ini menunjukkan bahwa implementasi bitswap dan transposisi acak mampu meningkatkan keacakan hasil enkripsi menggunakan VC pada citra RGB. Optimasi VC menggunakan bitswap dilakukan sebelum nilai piksel dienkripsi menggunakan VC serta setelah nilai hasil enkripsinya diperoleh. Bitswap secara signifikan meningkatkan hasil VC baik secara visual maupun matematis. Hasil optimasi ini selanjutnya dioptimasi kembali menggunakan transposisi acak yang juga meningkatkan keacakan hasil enkripsi dan secara visual menghilangkan seluruh ciri dari citra aslinya. Entropi hasil enkripsi terbesar adalah 7.9806 untuk citra baboon, sementara entropi rata-ratanya adalah 7.9582 dimana nilai ini sudah sangat mendekati 8 yang merupakan entropi terbesar dari sebuah citra. Demikian pula, nilai koefesien korelasinya yang memberikan nilai semakin mendekati 0 (nol) pada citra hasil enkripsi yang dioptimasi.

Meskipun secara matematis bitswap mampu meningkatkan kinerja VC secara signifikan, namun secara visual masih memperlihatkan sedikit dari karakteristik citra aslinya. Untuk itu, penelitian selanjutnya akan diarahkan untuk menemukan pola bitswap yang lebih baik agar dapat menghasilkan citra enkripsi yang optimal baik secara matematis maupun secara visual, tanpa melibatkan transposisi acak.

\section{DAFTAR PUSTAKA}

[1] S. D. Nasution, G. L. Ginting, M. Syahrizal, and R. Rahim, "Data Security Using Vigenere Cipher and Goldbach Codes Algorithm," Int. J. Eng. Res. Technol., vol. 6, no. 01, pp. 360-363, 2017.

[2] P. Subhasri and A. Padmapriya, "Enhancing the security of dicom content using modified vigenere cipher," Int. J. Appl. Eng. Res., vol. 10, no. 55, pp. 1951-1956, 2015.

[3] A. Susanto, T. Khotimah, M. T. Sumadi, J. Warsito, and R. Rihartanto, "Image encryption using vigenere cipher with bit circular shift," Int. J. Eng. Technol., vol. 7, no. 2.2 (2018), pp. 62-64, 2018.

[4] I. Saputra, Mesran, N. A. Hasibuan, and R. Rahim, "Vigenere Cipher Algorithm with Grayscale Image Key Generator for Secure Text File," Int. J. Eng. Res. Technol., vol. 6, no. 01, pp. 266-269, 2017.

[5] A. Rizal, D. S. B. Utomo, R. Rihartanto, and M. E. Hiswati, "Modified Key Using Multi-Cycle Key In Vigenere Cipher," Int. J. Recent Technol. Eng., vol. 8, no. 2S11, pp. 2600-2606, 2019.

[6] M. Octavianingrum, D. A. Siambaton, and A. F. K. Dewi, "Modifikasi vigenere cipher dengan kunci geser metode enkripsi blok," in Prosiding Seminar Nasional Matematika dan Pendidikan Matematika, 2018, pp. 234-239.

[7] A. Sutoyo, Nurhayati, and I. Gultom, "Implementasi Super Enkripsi Algoritma One Time Pad (OTP) Dan Beaufort Chiper Untuk Mengamankan Data," J. Sist. Inf. Kaputama, vol. 3, no. 1, pp. 1-5, 2019.

[8] H. E. Prabowo and A. Hangga, "Metoda Vigenere Chiper Double Columnar Transposition Sebagai Modifikasi Teknik Kriptografi Dalam Pembentukan Kunci," in Prosiding Seminar Nasional Sains Dan Teknologi (SNST), 2015, pp. 77-82.

[9] M. F. Syawal, D. C. Fikriansyah, and N. Agani, "Implementasi Teknik Steganografi Menggunakan Algoritma Vigenere Cipher Dan Metode LSB," J. TICOM, vol. 4, no. 3, pp. 91-99, 2016.

[10] A. Rizal, D. Susilo Budi Utomo, R. Rihartanto, and A. Susanto, "Encryption of RGB Image Using Hybrid Transposition," in Advances in Social Science, Education and Humanities Research, 2019, vol. 203, no. ICLICK 2018, pp. 57-61. 